\title{
A temperature-compensated ultradian clock ticks in Schizosaccharomyces pombe
}

\author{
Fred Kippert† and David Lloyd
}

Author for correspondence: David Lloyd. Tel: +44 1222 874772. Fax: +44 1222874305.

Microbiology Group (PABIO), University of Wales College of Cardiff, PO Box 915, Cardiff CF1 3TL, UK

\section{An ultradian oscillation is described for Schizosaccharomyces pombe which meets the criteria for a cellular clock, i.e. timekeeping device. The rhythm can be induced by transfer from circadian conditions (stationary phase or very slow growth) to ultradian conditions (rapid growth). It can also be synchronized by ultradian temperature cycles of $6^{\circ} \mathrm{C}$ difference. Released to constant temperature, the rhythm persists for $20 \mathrm{~h}$ without damping. The period of the free-running rhythm is temperature-compensated and in no experiment did period length fall outside the narrow range between $\mathbf{4 0}$ and $44 \mathrm{~min}$. The parameter observed is the septum index, i.e. the percentage of cells occupying the last stage of the cell cycle in wild-type cells before final division. The results suggest control of the cell division processes by the ultradian clock.}

Keywords: ultradian clock, cell cycle control, Schizosaccharomyces pombe, septum index, rhythm

\section{INTRODUCTION}

The archetypal biological clocks are the circadian thythms, found ubiquitously among eukaryotes from microbes to man (for a review, see Edmunds, 1988). They are self-sustained, endogenous thythms which fit a more restricted definition of the term 'clock' showing the properties of a timekeeping device: (1) they display a general homeostasis ensuring constant frequency (but not phase) irrespective of their environment, and (2) they are involved in temporal control of multiple aspects of cellular metabolism.

Although circadian rhythms are the most obvious expression of a cellular clock, a similar phenomenon can be found on a shorter time-scale. Ultradian rhythms have predominantly been studied in mammals and in lower eukaryotes (Lloyd \& Stupfel, 1991; Lloyd, 1992; Lloyd \& Kippert, 1993), but only in the latter has the idea of ultradian clocks attracted more attention. The most intensively studied example so far is the ultradian thythm in the soil amoeba Acantbamoeba castellanii with a period of around $70 \mathrm{~min}$ (for a review see Lloyd \& Edwards, 1984). In this microbe, rhythms in energy-demanding processes,

† Present address: Institute of Physiological Chemistry, University of Tabingen, Hoppe-Seyler Str. 4, 72076 Tübingen, Germany.

Abbreviations : LD, light-dark cycle; DD, continuous dark; LL, continuous light. such as transcription and translation, occur with a defined phase-relationship to those of energy-yielding processes, such as respiration. Similar ultradian oscillations with periods in the range of 30 to $70 \mathrm{~min}$ were also found in other diverse eukaryotic microbes such as Critbidia fasciculata (Edwards et al., 1975), Candida utilis (Lloyd et al., 1981), Chlamydomonas reinhardii (Jenkins et al., 1989), Tetrabymena pyriformis (Lloyd et al., 1978; Kippert, 1987) and Parameciun tetraurelia (Kippert, 1987). Another class of ultradian thythms with periods in the range of 4 to $5 \mathrm{~h}$ has also been found in eukaryotic microbes, e.g. Tetrabymena thermophila (Kämmerer \& Hardeland, 1982) and Euglena gracilis (Balzer et al., 1989a).

Being one of the most important aspects of a general homeostasis, temperature-compensation is perhaps the feature distinguishing a clock from a rhythm or an oscillation in general. In the ultradian range, this was first demonstrated for Acanthamoeba castellanii. Whereas generation time in this amoeba roughly doubled between $30^{\circ} \mathrm{C}$ and $20^{\circ} \mathrm{C}$, the period of the ultradian rhythm was far less dependent on temperature (Lloyd et al., 1982a; Lloyd \& Edwards, 1987). The rhythm in Tetrabymena pyriformis was found to be compensated over the temperature interval tested, i.e. between $19^{\circ} \mathrm{C}$ and $33^{\circ} \mathrm{C}$, with a $Q_{10}$ of $1 \cdot 12$, whereas culture growth rate displayed a $Q_{10}$ of 1.89 over this temperature range (Kippert, 1987). Temperature-compensation comparable to that of circadian rhythms was also found for the ultradian rhythms in Paramecium tetraurelia (Kippert, 1987), Tetrabymena 
thermophila (Michel \& Hardeland, 1985), and Euglena gracilis (Balzer et al., 1989a, b; Balzer \& Hardeland, 1992).

The study of the interaction between a circadian oscillator and the cell division cycle is of particular interest because one process is temperature-compensated whereas the other one is highly temperature-dependent. Growth of many micro-organisms shows a $Q_{10}$ of about 2 . As a consequence, generation time is increased twofold when temperature is lowered by $10^{\circ} \mathrm{C}$. For a given cell, however, this increase can only occur as increments of the entrained or free-running period of the circadian clock. This leads to the expression of quantized cell cycles, i.e. the interdivision time can only be an integer multiple of the circadian period. A similar link between an ultradian clock and the cell cycle was already predicted from the work of Lloyd and colleagues (Lloyd et al., 1982b), since their cultures showing ultradian rhythms in metabolism were synchronized by cell size selection, i.e. with respect to cell age in the cell division cycle. Direct evidence for a gating role of ultradian clocks came from a single-cell study with Paramecium tetraurelia which showed that interdivision times in this large ciliate were not randomly distributed but occurred rather in clusters $70 \mathrm{~min}$ apart (Lloyd \& Kippert, 1987).

Schizosaccbaromyces pombe has proven to be one of the most useful model organisms in cell cycle research (for a review, see Forsburg \& Nurse, 1991). For this yeast, there is a wealth of data about oscillations associated with the cell cycle (for a review see Mitchison, 1989). Unfortunately the results obtained in different, or even the same, laboratories are very contradictory. One important source of these differences in results may, as discussed by most authors, be the procedure chosen to obtain synchronous cultures. The major discrepancy between the results coming from the laboratories of Lloyd (Lloyd $e t$ al., 1982b) and Mitchison (Mitchison, 1989), respectively, is that in the former, oscillations always show more than one peak/step per cell cycle whereas in the latter, there is only one. Lloyd and colleagues found oscillations in respiration and enzyme activities with a cell cycle-specific pattern (Poole et al., 1973; Poole \& Lloyd, 1973; Edwards \& Lloyd, 1977; Poole, 1977; Bashford et al., 1980). Changes in the rate of oxygen uptake or carbon dioxide emission only once per cell cycle have been described by Novak \& Mitchison (1986, 1990). These periodicities persisted for at least two cycles after block to the DNAdivision cycle by addition of hydroxyurea, or by shifting $c d c$ mutants to the restrictive temperature (Novak \& Mitchison, 1986, 1990), and also after a block to protein synthesis (Novak \& Mitchison, 1987). In all of these cases the periodicities were either shortened or prolonged as compared to a normal cell cycle under the respective condition, which points to an oscillator that is entrained to the cell cycle under conditions of normal cell growth but becomes uncoupled and free-runs with a period different from that of the normal cell cycle when the DNA-division cycle is blocked.

Only recently, two circadian rhythms have been described for S. pombe (Kippert, 1989; Kippert \& Engelmann, 1989), including a circadian rhythm in cell division which can be followed in slowly growing cultures, i.e. those with a generation time equal to or exceeding $24 \mathrm{~h}$. The aims of the present study were to establish that an ultradian clock also operates in $S$. pombe and to investigate its basic characteristics.

\section{METHODS}

Organism and maintenance. The wild-type $972 \mathrm{~h}^{-}$strain of $S$. pombe used in this study (designated WT Tübingen) was derived from a culture (designated WT Cardiff) taken from Cardiff to Tübingen in 1988. Meanwhile it has become evident that this wild-type differs in several physiological aspects from wildtypes obtained from other sources.

Rather than the common practice in many laboratories of taking single clones, in our laboratory cells from several or even many colonies are always transferred to the new plate. This is to ensure that a spontaneous mutation affecting clock functions cannot be selected by chance. As nothing is known about possible clock mechanisms this seems an important cautionary measure. Also for all of the experiments described, inocula were always from several to many colonies.

Growth conditions. For all experiments on the septum index, cells were grown in the minimal medium MMC as described by Kippert et al. (1991). Carbon sources were added to the medium after autoclaving. Glucose was autoclaved separately, whereas xylulose was filter sterilized. Where not indicated otherwise, glucose was added to $2 \%(\mathrm{w} / \mathrm{v})$. With exception of the refeeding experiment, cultures had been in exponential phase for several generations before the experiment. At the beginning of the synchronization protocol, the cultures were appropriately diluted into medium prewarmed to the higher temperature of the synchronizing cycle. The dilution factor was variable, depending on the expected time-span of the experiment. In general, cell concentrations at the end of an experiment did not exceed $5 \times 10^{6}$ cells $\mathrm{ml}^{-1}$. Cultures were not aerated; this does not have any effect on the ultradian rhythm. Before taking samples, cultures were thoroughly shaken by hand to ensure homogeneous distribution of organisms.

Temperature and light. For all experiments cultures were kept in waterbaths, in which temperature was constant within $\pm 0 \cdot 2{ }^{\circ} \mathrm{C}$. In those experiments in which cultures had previously to be kept under circadian conditions (i.e. stationary phase or very slow growth), this was done in temperature-controlled rooms with temperature constant within $\pm 0.3^{\circ} \mathrm{C}$. In experiments involving temperature cycles, cultures were transferred between two waterbaths. Depending on culture volume, the new temperature in a cycle with $6^{\circ} \mathrm{C}$ difference was reached within 4 to $8 \mathrm{~min}$.

For circadian conditions, a $12 \mathrm{~h}$ light-dark cycle (LD 12:12) was applied. White light from Osram L65W/25A was at an intensity of between 2000 and 3000 lx measured at the surface of the culture flasks. The same light source and intensity was used for continuous light (LL); continuous darkness (DD) was achieved by wrapping the flasks in aluminium foil. For the experiments with ultradian light-dark cycles, light from Osram $\mathrm{XBO}=1600 \mathrm{~W} / \mathrm{P}$ Xenon lamps was at an intensity of $60000 \mathrm{~lx}$.

The synchronization protocol eventually developed and referred to as 'the routine procedure' used at least four temperature cycles of $15 \mathrm{~min}$ at $27^{\circ} \mathrm{C} / 30 \mathrm{~min}$ at $33^{\circ} \mathrm{C}$.

Microscopical analysis of septum index. Cells were fixed in $6 \%(\mathrm{v} / \mathrm{v})$ formaldehyde. Total cell number and number of cells showing a septum were counted in a Thoma counting chamber. For each time point, at least 1000 cells were analysed. 


\section{RESULTS AND DISCUSSION}

\section{Induction of the rhythm by transfer from circadian (non-growing) to ultradian conditions}

To monitor a rhythm in a population, it is a requirement to have good synchrony amongst the individual cells. For observation of ultradian rhythms in the 30 to $70 \mathrm{~min}$ range, two different approaches have been used previously. Firstly, cell size selection of a subpopulation: continuous-flow size selection has been successfully applied to the study of ultradian rhythms in a variety of eukaryotic microbes (for review see Lloyd \& Kippert, 1987). Secondly, easier synchronization is provided by the induction of an ultradian rhythm by the refeeding of stationary-phase cultures. This method was developed for Tetrabymena pyriformis (Kippert, 1987). Cultures of this ciliate grown to stationary phase and kept in the nongrowing state for several days in LD showed, after resuspension and dilution into fresh medium, an ultradian rhythm in respiration. This procedure is applied to $S$. pombe in the present study. Being particularly interested in interactions between the ultradian clock and cell cycle, we chose the septum index (which represents the percentage of dividing cells) as the easiest observable parameter.

A culture was grown in $\mathrm{MMC}$ at $30^{\circ} \mathrm{C}$ without shaking and, after reaching stationary phase, kept in an LD 12:12 for a further $3 \mathrm{~d}$. After that time, half of the culture was diluted 1:10 into fresh medium at the same temperature. Samples were taken every $6 \mathrm{~min}$ and the septum index was determined. Fig. 1(a) shows the pattern for this culture. After a lag phase of about $4 \mathrm{~h}$, cell division resumed and the septum index increased from zero. As expected from earlier studies from several laboratories, there was no good synchrony with respect to the cell cycle. Individual cell divisions were dispersed over a time-span of several hours. The overall decline in septum index after approximately $500 \mathrm{~min}$ probably represents the end of a first round of division before those cells that have divided earlier go into a second division. This assumption is supported by the increase in cell number, which had almost doubled by that time.

Superimposed on this general pattern was a periodic fluctuation in the septum index, which was however not very pronounced. One possible reason for this is that the lifetime of a septum in a dividing cell is quite long with respect to the period of the ultradian rhythm. According to the literature (Mitchison et al., 1963; Mitchison, 1970) it will be about $30 \mathrm{~min}$ at $30^{\circ} \mathrm{C}$, ranging from $29 \mathrm{~min}$ at $32{ }^{\circ} \mathrm{C}$ to $78 \mathrm{~min}$ at $17^{\circ} \mathrm{C}$ in defined medium. If the average lifetime of an individual cell septum is $30 \mathrm{~min}$ it will be visible at five to six successive time points in a single living cell. Fig. 1(b) shows a simulation of the data from Fig. 1(a) assuming that it was possible to assign the initiation of septum formation to a distinct interval of 6 min. Rhythmicity now becomes much more clear-cut, with a period of $44 \mathrm{~min}$.

The second half of the culture was kept in stationary phase under the same LD conditions for another $7 \mathrm{~d}$ before it was likewise transferred and diluted into fresh medium. The pattern in septum index resulting from this transfer is

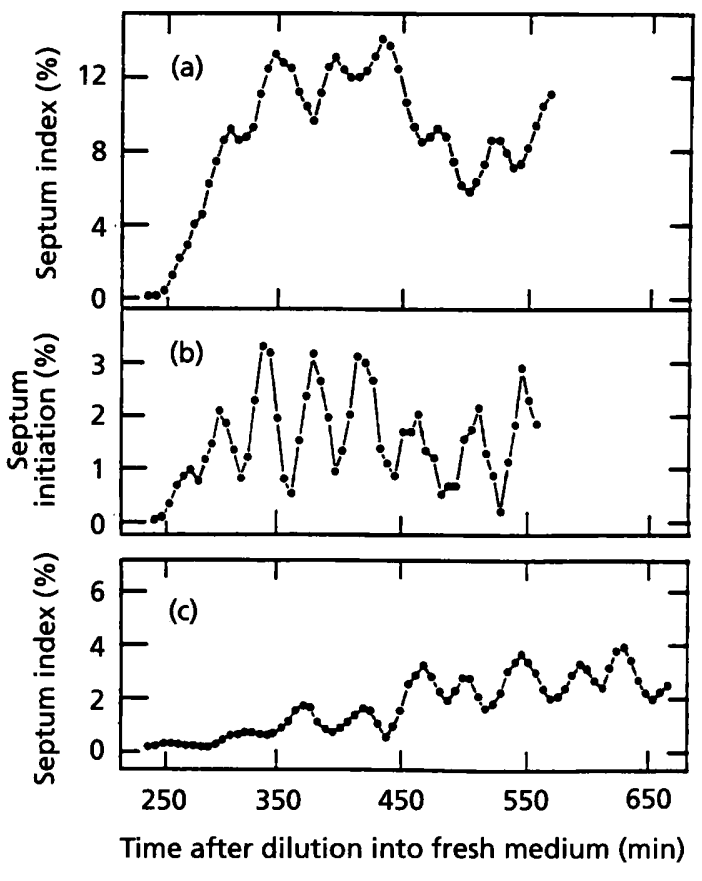

Fig. 1. Induction of the ultradian rhythm in septum index after refeeding of stationary phase cultures. Cultures that had been kept in stationary phase (in an LD regime) for $3 \mathrm{~d}$ (a) or $10 \mathrm{~d}$ (c) were diluted into fresh medium at time zero. The temperature before and after this transfer was constant $\left(30^{\circ} \mathrm{C}\right)$. (b) Simulation of the original data shown in (a), assuming that the initiation of a septum (expected to be detectable over a total of $30 \mathrm{~min}$ ) could be assigned to a 6 min interval.

shown in Fig. 1(c). As expected, the increase in septum index was retarded. In addition, the mean percentage was much lower, which probably represents a far greater dispersion in the lag phase between individual cells; this was also indicated by the total cell counts. The rhythmic pattern was, however, quite comparable to that of the culture transferred after $3 \mathrm{~d}$ and showed a period of $43 \mathrm{~min}$.

The induction of an ultradian rhythm by refeeding of stationary-phase $S$. pombe cultures thus works as well as it did with T. pyriformis (Kippert, 1987). Since it is a very simple method, it may have wider applicability in those cases where the period length has yet to be determined for a newly studied micro-organism.

\section{Induction of the rhythm by transfer from circadian (slowly growing) to ultradian conditions}

The transfer of cells from stationary phase (circadian conditions) to rapid growth (ultradian conditions) produces an unacceptably long lag phase. It would, therefore, be desirable to shift cells not from stationary phase but from slow (circadian) to faster (ultradian) growth conditions. The major problem here is to have the cells growing slowly enough at reasonable laboratory temperatures to express a circadian rhythm in cell division (i.e. with a generation time of at least $24 \mathrm{~h}$ ). The only condition found so far which reproducibly permits very slow 


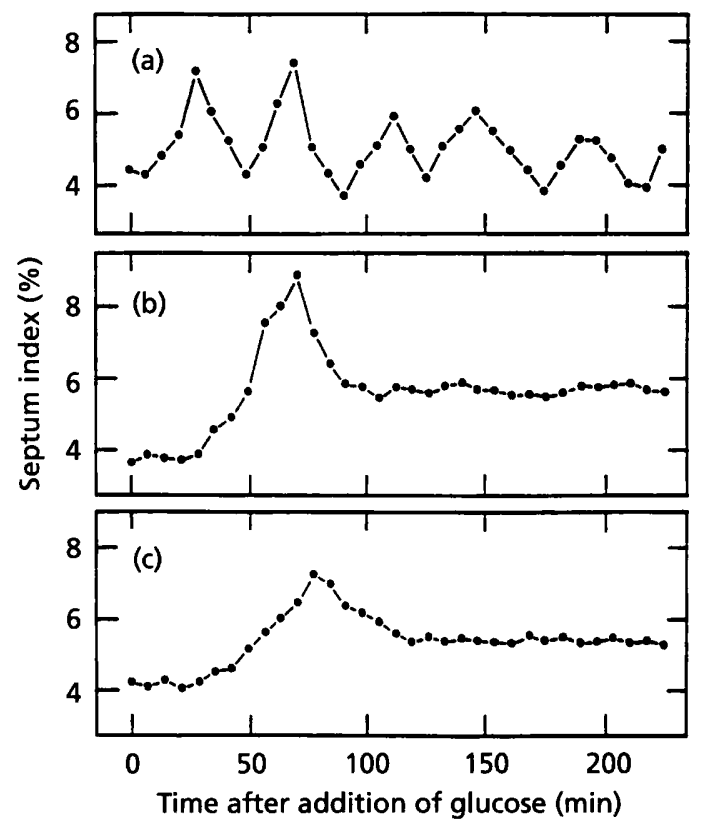

Fig. 2. Induction of the ultradian rhythm in septum index after addition of glucose to cultures grown previously on xylulose as carbon source in a light-dark cycle (a), continuous light (b) or constant darkness (c).

growth at higher temperatures in batch cultures is the use of xylulose as carbon source. Growth rates on xylulose are quite different for different yeast species (Wang \& Schneider, 1980); in Saccharomyces cerevisiae for example generation time is prolonged to $30 \mathrm{~h}$ at $30{ }^{\circ} \mathrm{C}$ and about the same slowing down of growth has also been observed for the $S$. pombe strain used in this study (F. Kippert, unpublished).

A culture was grown for several days at $30{ }^{\circ} \mathrm{C}$ in an $\mathrm{LD}$ $12: 12$ regime in $\mathrm{MMC}$ with $0.5 \%$ xylulose as carbon source. Glucose was then added, at the middle of the light period, to a final concentration of $2 \%$, and the incubation was continued at the same temperature. Fig. 2(a) shows the septum index after addition of glucose; it fluctuated periodically with a period length of approximately $42 \mathrm{~min}$. This result indicates that this type of experiment provides a powerful approach since the same overt rhythm is observed before and after the addition, albeit controlled by two different clocks. In particular, this procedure may be very useful to address the question about the relationship between ultradian and circadian thythms.

Earlier experiments with Tetrabymena pyriformis indicated that an LD during the time the culture was kept under circadian conditions was a prerequisite for the ultradian rhythm to become apparent after transfer to fresh medium (F. Kippert, unpublished). To test whether this is also true for $S$. pombe, two parallel cultures were inoculated but kept in LL or DD during their growth on xylulose. The changes in septum indices for these cultures after addition of glucose are shown in Figs 2(b) and (c), respectively; no rhythmicity could be detected under either condition.

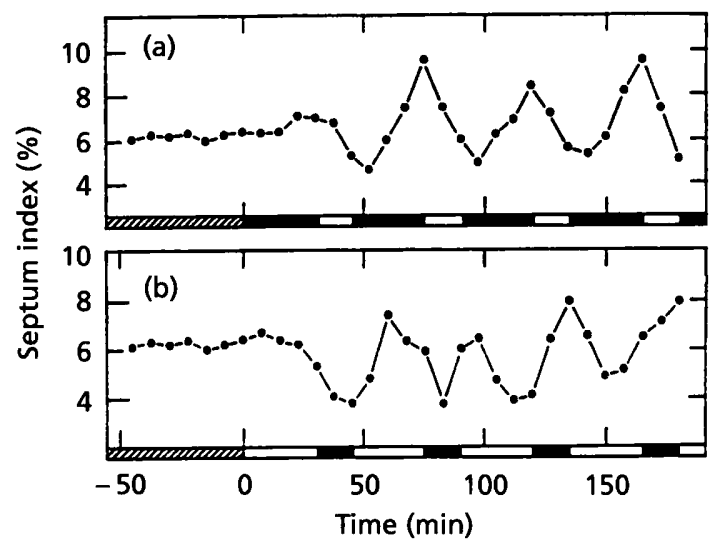

Fig. 3. Synchronization of the ultradian rhythm in septum index by temperature cycles of $27^{\circ} \mathrm{C}$ (open bars) and $33^{\circ} \mathrm{C}$ (filled bars) after previous growth at $30^{\circ} \mathrm{C}$ (hatched bars). Apportionment between upper and lower temperature is $30: 15 \mathrm{~min}(\mathrm{a})$, or $15: 30 \mathrm{~min}(\mathrm{~b})$.

With respect to the overall pattern of septum index, in all three cases it rose from about $4 \%$. These cannot, however, be regarded as being equivalent. In cultures entrained to an $\mathrm{LD}$, the septum index is increasing at this time during the course of its circadian rhythm (F. Kippert, unpublished). Under constant conditions, $4 \%$ represents the level of septum index which is not altered throughout the day in the non-synchronized cultures.

\section{Synchronization by ultradian temperature cycles}

For routine experiments, a simple and efficient procedure for synchronization was developed which is amenable to automation. Knowing the period length of the ultradian clock, it was easy to test temperature changes as a synchronizing agent. Kämmerer \& Hardeland (1982) were able to synchronize the $5 \mathrm{~h}$ rhythm in tyrosine aminotransferase activity in Tetrabymena thermophila by subjecting the cultures to a rather crude temperature regime, i.e. $4 \mathrm{~h}$ at $20^{\circ} \mathrm{C}$ and $1 \mathrm{~h}$ at $0^{\circ} \mathrm{C}$. Since this procedure must also produce considerable perturbation of cell metabolism, a more gentle temperature cycle seemed preferable. It was found that the ultradian rhythm in rapidly growing cultures of $S$. pombe is easily synchronized by temperature cycles with $6{ }^{\circ} \mathrm{C}$ difference between lower and upper temperature. Fig. 3 shows ultradian rhythms observed after temperature cycles of $15 \mathrm{~min}$ at $27^{\circ} \mathrm{C} / 30 \mathrm{~min}$ at $33^{\circ} \mathrm{C}(\mathrm{a})$, or $30 \mathrm{~min}$ at $27^{\circ} \mathrm{C} / 15 \mathrm{~min}$ at $33^{\circ} \mathrm{C}$ (b). In both cases synchronization appeared to be complete after three cycles. For all further experiments, cultures were exposed to at least four temperature cycles.

The finding that the $S$. pombe ultradian clock is readily observed after treatment using rather mild temperature cycles opens great potential for further studies. With an automatic exchange between two waterbaths (also suitable for larger volumes) the cultures can conveniently be synchronized overnight. An additional advantage of this procedure is that it is unlikely to cause any perturbations 


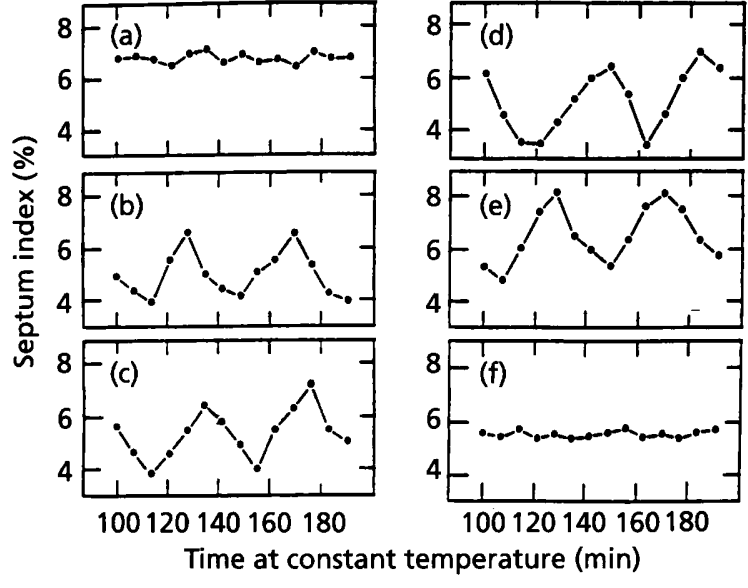

Fig. 4. Range of entrainment. Presence or absence of the ultradian rhythm in septum index in free-run at $30^{\circ} \mathrm{C}$ after temperature cycles with equal time spent at higher $\left(33^{\circ} \mathrm{C}\right)$ and lower $\left(27^{\circ} \mathrm{C}\right)$ temperature. Total cycle length was (a) $20 \mathrm{~min}$, (b) $24 \mathrm{~min},($ c) $30 \mathrm{~min},(\mathrm{~d}) 60 \mathrm{~min},(\mathrm{e}) 70 \mathrm{~min},(\mathrm{f}) 80 \mathrm{~min}$.

since both temperatures employed, i.e. $27^{\circ} \mathrm{C}$ and $33^{\circ} \mathrm{C}$, are well within the range favourable for rapid growth of S. pombe.

Synchronization of the ultradian clock by temperature cycles is extremely reproducible. However, it was found that the phase-relationship of the rhythm in septum index to the temperature cycle was variable. The most likely explanation seems that septum formation is not itself controlled by the clock but is rather some way downstream of the actual clock-controlled process, presumably mitosis; there is now evidence that clock control is on the p34 ${ }^{\text {cdc } 2+}$ kinase network (authors' unpublished observations). Compared with the period length of the ultradian rhythm, septum formation and cell division are separated by a considerable time-span from mitosis, during which the exogenous temperature cycle may exert various effects on all processes occurring between mitosis and septum formation; different phase-relationships at, for example, different growth rates are therefore not too surprising.

In the light of the rapid entrainment by temperature cycles, it was of interest to determine whether a single, more extreme temperature treatment would be sufficient to synchronize the ultradian clock; $20 \mathrm{~min}$ on ice as well as $10 \mathrm{~min}$ or $20 \mathrm{~min}$ at $42.5^{\circ} \mathrm{C}$ failed to synchronize the ultradian rhythm (data not shown).

The capability of exogenous cycles to synchronize circadian clocks depends on both their amplitude and period length. As a rule, cycles shorter than $20 \mathrm{~h}$ or longer than $28 \mathrm{~h}$ are hardly, or not at all, effective in entrainment. The effectiveness of different ultradian temperature cycles is shown in Fig. 4. Cells were synchronized for six cycles with one half of the cycle at $27^{\circ} \mathrm{C}$ and the other half at $33{ }^{\circ} \mathrm{C}$ and then released to a constant temperature of $33^{\circ} \mathrm{C}$. The occurrence of rhythmicity was only monitored in free-run, as a periodic fluctuation of septum index through the temperature cycle would not necessarily

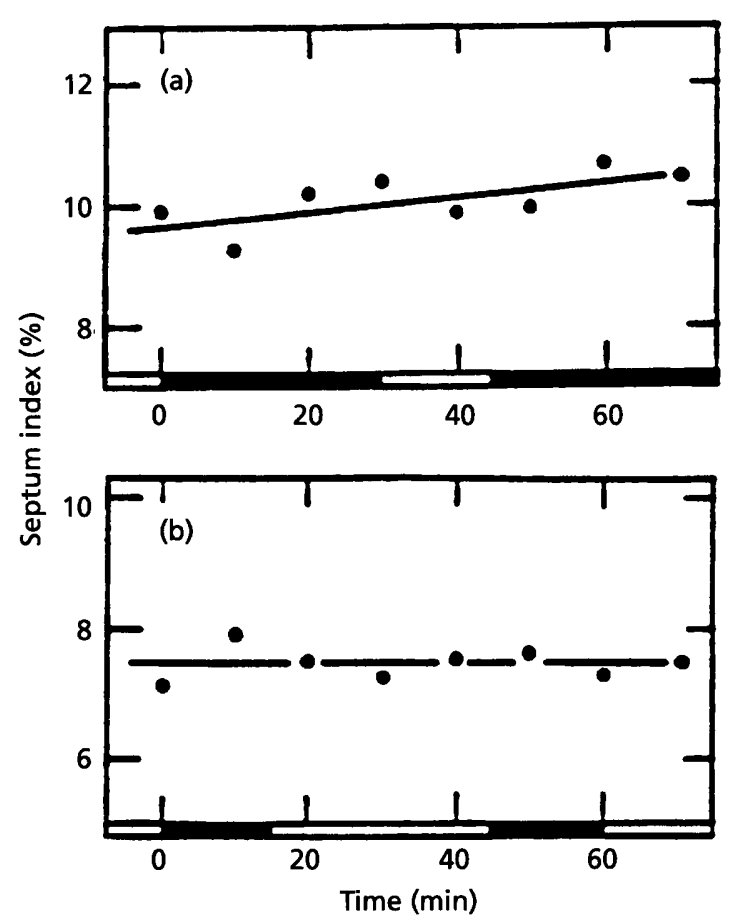

Fig. 5. Lack of synchronization by ultradian light-dark cycles. Light intensity during the light phase was about $60000 \mathrm{~lx}$. Light-dark cycles were 15:30 min (a), or 30:15 min (b).

reflect synchronization of the ultradian clock, but could simply be due to direct temperature effects on physiological processes, i.e. mitosis or septum formation. Whereas cycles with a total length of 24 (Fig. $4 \mathrm{~b}$ ) and $30 \mathrm{~min}$ (c) could synchronize the ultradian clock, a cycle of $20 \mathrm{~min}$ (a) was ineffective. The efficiency of longer cycles is given in the right of Fig. 4. Cycles of 60 (d), and $70 \mathrm{~min}(\mathrm{e})$, did synchronize whereas a cycle of $80 \mathrm{~min}(\mathrm{f})$, did not. The broad range of entrainment (i.e. at least between 24 and $70 \mathrm{~min}$ ) for the ultradian clock of $S$. pombe clearly contrasts that usually found for circadian rhythms. However, the range of entrainment of the circadian clock of $S$. pombe has not been determined, and it is not yet possible to make any final statement about similarity or dissimilarity between the two clocks.

Light is the strongest Zeitgeber (time-setting signal) for most circadian clocks; we therefore tested whether the ultradian rhythm of $S$. pombe could be entrained by ultradian LD cycles. Since an LD with moderate light intensities did not have any effect, an LD regime at a light intensity of $60000 \mathrm{~lx}$ during the light phase was applied. This is almost the intensity that can decrease the growth rate of $S$. pombe at $30^{\circ} \mathrm{C}$ (Kippert $e t$ al., 1991). Even after more than 20 ultradian $\mathrm{LD}$ cycles no synchronization was observed in the septum index at either LD 30:15 min or LD 15:30 min, as shown in Fig. 5. This experiment also gives a good indication of the accuracy of the determination of the septum index. The incapacity of ultradian light-dark cycles to synchronize the ultradian clock indicates an important difference from circadian rhythms (Kippert, 1992a). For circadian rhythms the ability to 


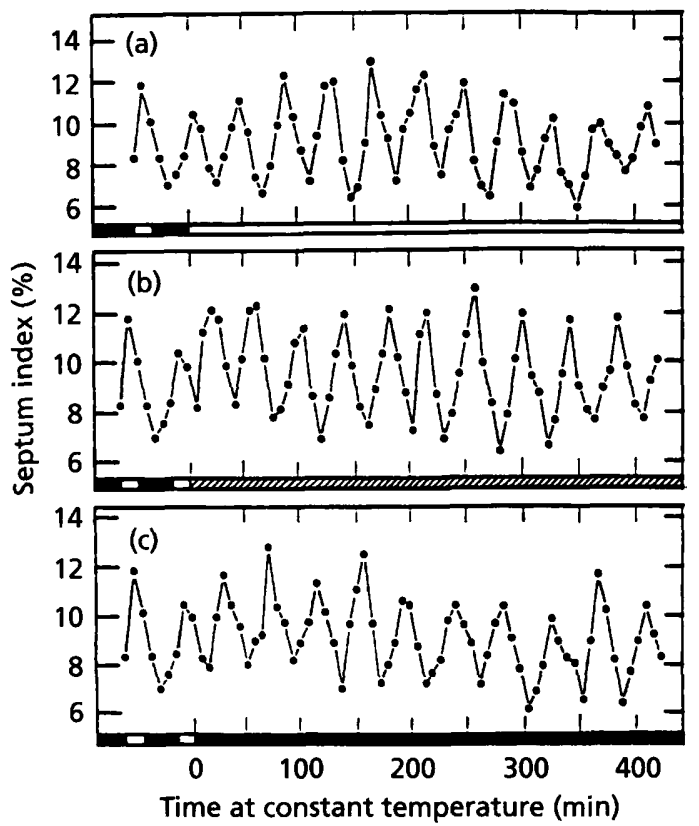

Fig. 6. Temperature-compensation of the ultradian rhythm in septum index. After the standard synchronization procedure parallel cultures were transferred to $26^{\circ} \mathrm{C}$ (a, open bar), $30^{\circ} \mathrm{C}$ (b, hatched bar), or $34^{\circ} \mathrm{C}$ (c, filled bar).

entrain to the exogenous daily cycle of light and darkness is paramount for daily resetting of a rhythm which usually has a period of not exactly $24 \mathrm{~h}$ duration. For ultradian rhythms nothing equivalent seems feasible as there is no corresponding geophysical cycle. Therefore, it appears plausible to assume that an input pathway from the photoreceptor(s) of $S$. pombe to the ultradian clock is not necessary and may not exist.

\section{Temperature-compensation - general homeostasis}

Temperature-compensation is an important feature distinguishing a clock from an oscillator; it provides the decisive indication that we are dealing with a timekeeping device. It was therefore essential to test whether the ultradian rhythm of $S$. pombe fulfils this requirement for classification as a clock. Cultures synchronized by temperature cycles of $30 \mathrm{~min}$ at $33^{\circ} \mathrm{C} / 15 \mathrm{~min}$ at $27^{\circ} \mathrm{C}$ were shifted to constant temperatures of $26^{\circ} \mathrm{C}$ (Fig. 6a), $30^{\circ} \mathrm{C}$ (b) or $34^{\circ} \mathrm{C}$ (c), respectively. It is immediately evident that there is hardly any difference between the periods of the free-running rhythm at these three temperatures. The results of periodogram analysis using maximum entropy spectrum analysis (MESA) are shown in Fig. 7. Period lengths at $26{ }^{\circ} \mathrm{C}, 30^{\circ} \mathrm{C}$ and $34^{\circ} \mathrm{C}$ are $40.4 \mathrm{~min}, 40.2 \mathrm{~min}$ and $42.0 \mathrm{~min}$, respectively. The ultradian clock of $S$. pombe is obviously well temperature-compensated. Quantitative statement about the $Q_{10}$ value is inappropriate as measurements have only been made at these three temperatures. To establish an exact dependency of period length on temperature it would be necessary to perform a much larger number of long-term experiments, and to do this also at intermediate temperatures. However, the exact
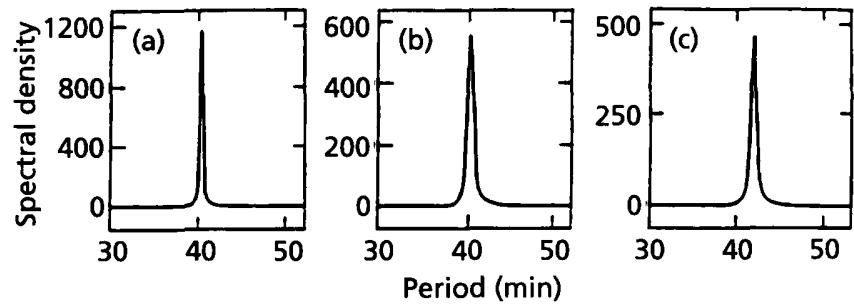

Fig. 7. Periodogram analyses (MESA) of the data from the temperature-compensation experiment shown in Fig. 6. (a) $26^{\circ} \mathrm{C}$, (b) $30^{\circ} \mathrm{C}$, (c) $34^{\circ} \mathrm{C}$. Spectral density is given in arbitrary units.

slope of this dependency curve would provide little additional information. The important fact to stress here is that the ultradian clock of $S$. pombe shows a temperaturecompensation with an efficiency which rivals that usually associated with circadian rhythms. From a phylogenetic point of view, it is interesting to note that the temperaturecompensation displayed by $S$. pombe appears to be better than that of the circadian clock of the fungus Neurospora crassa, which itself is rather an exception amongst fungi, where endogenous rhythms are often not temperaturecompensated (Lysek, 1984).

Summarizing the results of the synchronization experiments, the ultradian thythm in $S$. pombe can be synchronized (or induced) by three different procedures: transfer from stationary phase (a circadian condition) to rapid growth, transfer from slow (circadian) to rapid (ultradian) growth, and exposure to ultradian temperature cycles. Remarkably, in all three cases, the period is virtually identical, i.e. slightly longer than $40 \mathrm{~min}$. This points to an independence of period length from the history of the culture and the method of synchronization. In fact, in more than 60 experiments carried out thus far with this strain, there was not a single experiment in which the period deviated from the range of 40 to $44 \mathrm{~min}$ (authors' unpublished observations).

\section{Long-term persistence}

The curves in Fig. 6 also show another interesting aspect. There is little, if any, damping over 10 cycles. This indicates that the clock is very stable in free-run, and that either the clock is very exact with minute deviation from one cell to the next, or there is intercellular communication. To address this feature in more detail, a culture was synchronized by the standard procedure and followed (with intermission) for $18.5 \mathrm{~h}$ at $33^{\circ} \mathrm{C}$. The result is shown in Fig. 8. Assuming a period of $42 \mathrm{~min}$, the last cycle of this experiment would be cycle number 26 . At first glance there seems to be a little damping of the rhythm. However, if one calculates the amplitude as the maximum values divided by the minimum values there is no significant difference between the early and the late cycles in free-run. The lower mean index after $900 \mathrm{~min}$ is probably due to the fact that the culture at that time had already approached the end of its exponential phase, which is associated with slower growth. 


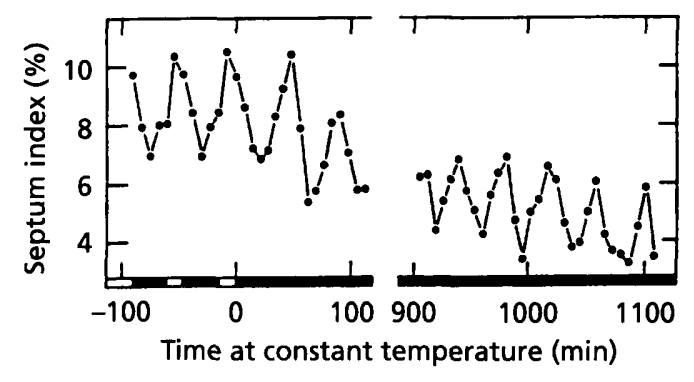

Fig. 8. Long-term persistence of the ultradian rhythm in septum index. Free-run (at $33^{\circ} \mathrm{C}$ ) after standard synchronization procedure is shown from 0 to $109 \mathrm{~min}$, and again from 900 to $1100 \mathrm{~min}$.

Synchronization by any unnoticed exogenous physical factor can be excluded since there are differences in period lengths between different strains, e.g. WT Cardiff, $46 \mathrm{~min}$; WT Tübingen, 40 to $44 \mathrm{~min}$; WT EMBL, $35 \mathrm{~min}$ (Kippert, 1992b). Therefore, two general explanations are possible for the observed long-term persistence of the ultradian rhythm. Firstly, the clock is extraordinarily precise; secondly, there is intercellular communication. Nanjundiah (1986) calculated how big the variation in period among individual cells may be if the amplitude drops to $50 \%$ within a given number of cycles. For the experiment shown in Fig. 8 it seems unreasonable to expect a $50 \%$ reduction before at least cycle number 50 . In that case, the variation in the period among individual cells would be $0.36 \%$, i.e. less than $10 \mathrm{~s}$.

A more likely explanation seems intercellular communication. The only organism in which precision of the circadian clock has been studied is the dinoflagellate Gonyaulax polyedra. Again calculating from the damping of the rhythm, Njus $e t$ al. (1981) concluded that the variation in the period among individual cells was about $18 \mathrm{~min}$, i.e. $1 \%$. At that time the authors interpreted the observed damping as evidence against intercellular communication. A later study employing mixing experiments questioned that view (Broda et al., 1986). The pattern in mixed cultures differed from the calculated sum of the two control cultures. Since this could be prevented by changing the medium, crosstalk between the cells was postulated.

Whatever the answer will be, it will have functional implications. If there is no communication, one would have to look for a clock mechanism which is precise within $10 \mathrm{~s}$. If there is communication, it would be worthwhile to search for the synchronizing factor. Tracking down the information pathway could eventually provide hints about the clock mechanism itself.

\section{General conclusions}

In the present paper we have described an ultradian rhythm in $S$. pombe which shows the characteristics of a cellular 'clock'. Its homeostasis, as exemplified by the temperature-compensation of its period, is not inferior to that of circadian rhythms. It may be involved in the control of a fundamental cellular function, the cell cycle. For a study of the gating functions of both circadian and ultradian clocks exerted on the cell cycle, $S$. pombe should prove an excellently suited model organism, especially with current increasing understanding of its regulatory mechanisms. More generally, $S$. pombe may be an ideal organism for the genetic and molecular dissection of clock mechanisms.

\section{REFERENCES}

Balzer, I. \& Hardeland, R. (1992). Multiple ultradian frequencies in dark motility of Euglena. J Interdiscip Cycle Res 23, 47-55.

Balzer, I., Neuhaus-Steinmetz, U. \& Hardeland, R. (1989a). Temperature-compensation in an ultradian rhythm of tyrosine aminotransferase activity in Euglena gracilis Klebs. Experientia 45, 476-477.

Balzer, I., Neuhaus-Steinmetz, U., Quentin, E., van Wülen, M. \& Hardeland, R. (1989b). Concomitance of circadian and circa-4-hour ultradian rhythms in Euglena gracilis. I Interdiscip Cycle Res 20, 15-24.

Bashford, C. L., Chance, B., Lloyd, D. \& Poole, R. K. (1980). Oscillations of redox state in synchronously dividing cultures of Acanthamoeba castellanii and Schizosaccharomyces pombe. Biopbys J 29, 1-12.

Broda, H., Brugge, D., Homma, K. \& Hastings, J. W. (1986). Circadian communication between unicells? Effects on period by cell-conditioning of medium. Cell Biophys 8, 47-67.

Edmunds, L. N., Jr (1988). Cellular and Molecular Bases of Biological Clocks. Models and Mechanisms for Circadian Timekeeping. New York: Springer.

Edwards, C., Statham, M. \& Lloyd, D. (1975). The preparation of large-scale synchronous cultures of the trypanosomatid, Crithidia fasciculata, by cell-size selection: changes in respiration and adenylate charge through the cell cycle. J Gen Microbiol 88, 141-152.

Edwards, S.W. \& Lloyd, D. (1977). Mitochondrial adenosine triphosphatase of the fission yeast, Schizosaccharomyces pombe $972 \mathrm{~h}^{-}$. Changes in activity and oligomycin-sensitivity during the cell cycle of catabolite-repressed and de-repressed cells. Biochem J 162, 39-46.

Forsburg, S. L. \& Nurse, P. (1991). Cell cycle regulation in the yeasts Saccharomyces cerevisiae and Schizosaccharomyces pombe. Annu Rev Cell Biol 7, 227-256.

Jenkins, H. A., Griffiths, A. J. \& Lloyd, D. (1989). Simultaneous operation of ultradian and circadian rhythms in Chlamydomonas reinhardii. J Interdiscip Cycle Res 20, 257-264.

Kămmerer, J. \& Hardeland, R. (1982). On the chronobiology of Tetrabymena. I. Ultradian rhythmicity in tyrosine aminotransferase activity. J Interdiscip Cycle Res 13, 297-302.

Kippert, F. (1987). Temperature-compensation of ultradian rhythms in ciliates. In Cbronobiology and Chronomedicine, pp. 60-64. Edited by G. Hildebrandt, R. Moog \& F. Raschke. Frankfurt: Verlag Peter Lang.

Kippert, F. (1989). Circadian control of heat tolerance in stationary phase cultures of Schizosaccharomyces pombe. Arch Microbiol 151, $177-179$.

Kippert, F. (1992a). Ultradian and circadian clocks - two sides of one coin? J Interdiscip Cycle Res 23, 192-196.

Kippert, F. (1992b). The ultradian clock and the cell cycle in Schizosaccharomyces pombe. MPhil thesis, University of Wales.

Kippert, F. \& Engelmann, W. (1989). A circadian clock controls the cell division cycle of Schizosaccharomyces pombe growing at low temperature. Eur J Cell Biol 48 (Suppl. 26), 81. 
Kippert, F., Ninnemann, H. \& Engelmann, W. (1991). Photosynchronization of the circadian clock of Schizosaccharomyces pombe: mitochondrial cytochrome $b$ is an essential component. Curr Genet 19, 103-107.

Lloyd, D. (1992). Intracellular timekeeping: epigenetic oscillations reveal the functions of an ultradian clock. In Ultradian Rbythms in Life Processes, pp. 5-22. Edited by D. Lloyd \& E. R. Rossi. London: Springer-Verlag.

Lloyd, D. \& Edwards, S. W. (1984). Epigenetic oscillations during the cell cycles of lower eukaryotes are coupled to a clock. Life's slow dance to the music of time. In Cell Cycle Clocks, pp. 27-46. Edited by L. N. Edmunds. New York: Marcel Dekker.

Lloyd, D. \& Edwards, S.W. (1987). Temperature-compensated ultradian rhythms in lower eukaryotes: timers for cell cycle and circadian events? In Advances in Cbronobiology, Part A, pp. 131-151. Edited by J. E. Pauly \& L. E. Scheving. New York: Alan R. Liss.

Lloyd, D. \& Kippert, F. (1987). A temperature-compensated ultradian clock explains temperature-dependent quantal cell cycle times. Symp Soc Exp Biol 40, 135-155.

Lloyd, D. \& Kippert, F. (1993). Intracellular coordination by the ultradian clock. Cell Biol Internat 17, 1047-1052.

Lloyd, D. \& Stupfel, M. (1991). The occurrence and functions of ultradian rhythms. Biol Rev 66, 275-299.

Lloyd, D., Phillips, C. A. \& Statham, M. (1978). Oscillations of respiration, adenine nucleotide levels and heat evolution in synchronous cultures of Tetrabymena pyriformis ST prepared by continuous-flow selection. J Gen Microbiol 106, 19-26.

Lloyd, D., Edwards, S. W. \& Williams, J. L. (1981). Oscillatory accumulation of total cellular protein in synchronous cultures of Candida utilis. FEMS Microbiol Lett 12, 295-298.

Lloyd, D., Edwards, S. W. \& Fry, J. C. (1982a). Temperaturecompensated oscillations in respiration and cellular protein content in synchronous cultures of Acanthamoeba castellanii. Proc Natl Acad Sci US A 79, 3785-3788.

Lloyd, D., Poole, R. K. \& Edwards, S. W. (1982b). The Cell Division Cycle: Temporal Control of Cellular Growth and Reproduction. London: Academic Press.

Lysek, G. (1984). Physiology and ecology of growth and sporulation in fungi. Symp Br Mycol Soc 8, 323-342.

Michel, U. \& Hardeland, R. (1985). On the chronobiology of Tetrabymena. III. Temperature compensation and temperature dependence in the ultradian oscillation of tyrosine aminotransferase. $J$ Interdiscip Cycle Res 16, 17-23.

Mitchison, J. M. (1970). Physiological and cytological methods for Schizosaccharomyces pombe. Methods Cell Biol Physiol 4, 131-165.

Mitchison, J. M. (1989). Cell cycle growth and periodicities. In Molecular Biology of the Fission Yeast, pp. 205-242. Edited by A. Nasim, P. Young \& B. F. Johnson. New York: Academic Press.

Mitchison, J. M., Kinghorn, M. L. \& Hawkins, C. (1963). The growth of single cells. IV. Schizosaccharomyces pombe at different temperatures. Exp Cell Res 30, 521-527.

Nanjundiah, V. (1986). How rapidly do uncoupled oscillators desynchronize? J Theor Biol 121, 375-379.

Njus, D., Gooch, V. D. \& Hastings, J. W. (1981). Precision of the Gonyaulax circadian clock. Cell Biophys 3, 223-231.

Novak, B. \& Mitchison, J. M. (1986). Change in the rate of $\mathrm{CO}_{2}$ production in synchronous cultures of the fission yeast Scbizosaccharomyces pombe: a periodic cell cycle event that persists after the DNA-division cycle has been blocked. J Cell Sci 86, 191-206.

Novak, B. \& Mitchison, J. M. (1987). Periodic cell cycle changes in the rate of $\mathrm{CO}_{2}$ production in the fission yeast Schizosaccharomyces pombe persist after a block to protein synthesis. J Cell $S_{c i} 87$, 323-325.

Novak, B. \& Mitchison, J. M. (1990). Changes in the rate of oxygen consumption in synchronous cultures of the fission yeast Schizosaccharomyces pombe. J Cell Sci 96, 429-433.

Poole, R. K. (1977). Development of respiratory activity during the cell cycle of Schizosaccharomyces pombe $972 \mathrm{~h}^{-}$: respiratory oscillations and heat dissipation in cultures synchronized with $2^{\prime}$ deoxyadenosine. J Gen Microbiol 103, 19-27.

Poole, R. K. \& Lloyd, D. (1973). Oscillations of enzyme activities during the cell cycle of a glucose-repressed fission yeast Scbizosaccharomyces pombe $972 \mathrm{~h}^{-}$. Biochem J 136, 195-207.

Poole, R. K., Lloyd, D. \& Kemp, R. B. (1973). Respiratory oscillations and heat evolution in synchronously dividing cultures of the fission yeast Schizosaccharomyces pombe $972 \mathrm{~h}^{-}$. J Gen Microbiol 77, 209-220

Wang, P. Y. \& Schneider, H. (1980). Growth of yeasts on Dxylulose. Can J Microbiol 26, 1165-1168.

Received 4 July 1994; revised 8 November 1994; accepted 5 December 1994. 